\title{
61. SULFUR AND CARBON ISOTOPE RATIOS OF DACITE AND RHYOLITE CONGLOMERATES FROM SITE 439, LEG 57, DEEP SEA DRILLING PROJECT
}

\author{
Hitoshi Sakai, Institute for Thermal Spring Research, Okayama University, Misasa, Tottori-Ken, Japan \\ and
}

Akira Ueda, Department of Petrology, Mineralogy and Economic Geology, Tohoku University, Sendai, Japan

\begin{abstract}
The sulfur content of one rhyolite and four dacite conglomerates was found to be low - from 9 to $97 \mathrm{ppm}$ - similar to that of Quaternary andesites and basalts of the Japanese Islands. However, the $\delta^{34} \mathrm{~S}$ values of these samples are unexpectedly high -+23 to +35 per mill - relative to troilite from the Canon Diablo meteorite. The sulfide/sulfate ratios vary among the five samples from 0 to 13 . No significant isotope fractionation seems to exist between sulfate and sulfide sulfurs. Carbon in these samples is predominantly in the form of carbonate (and probably $\mathrm{CO}_{2}$ ). It ranges in concentration from 128 to $721 \mathrm{ppm}$ and in $\delta^{13} \mathrm{C}$ from -2.5 to -20.7 per mill relative to PDB.
\end{abstract}

\section{INTRODUCTION}

The contents and stable isotope ratios of sulfur in Quaternary volcanic rocks of the Japanese Islands show sharp contrast with those of fresh basalts at mid-ocean ridges and in Iceland and Hawaii. Concentrations of volatile elements in the former (Ueda and Sakai, unpublished data) are very much lower than in the latter (Moore and Fabbi, 1971; Sakai et al,, 1978). In the former, sulfate sulfur often predominates over sulfide sulfur, whereas in the latter the reverse is always the case. The ${ }^{34} \mathrm{~S}$ values of the island arc volcanic rocks are about 0 to +5 per mill (Ueda and Sakai, unpublished data), whereas those of fresh basalts from the ocean floor (Kanehira et al., 1973; Grinenko et al., 1975; Sakai et al., 1978), from Hawaii, (Ueda, and Sakai, unpublished data), and from Iceland (Sakai, Ueda, and Tomasson, unpublished data) range from -0.5 to +1 per mill. In quite a few samples of ocean floor basalts, however, the stable isotope ratios of sulfur, especially those of epigenetic pyrite, show a significant deviation from the normal values (Field et al., 1976; Krouse et al., 1977; Sakai et al., 1978). Those authors have posited various mechanisms of isotope fractionation to interpret the unusual values. They suggest that the stable isotope ratios as well as the concentrations of volatile elements in volcanic rocks may be useful in assessing the origin and environment of eruption of the rocks and their depositional and diagenetic processes.

During Leg 57, conglomerate beds of rhyolitic and dacitic compositions were cored at Sites 438 and 439. Petrological and geological evidence suggests that these rocks belong to tholeiite and calc-alkaline rock series typical to an island arc system and erupted subaerially near the site of collection (Fujioka, this volume). These rocks are the first acid rocks that have been collected by the Deep Sea Drilling Project. The age of the acid conglomerates is about 21 m.y. (uppermost Oligocene to the lowermost Miocene (Ozima and Yanagisawa, this volume). The purpose of this study is to analyze the concentrations and the isotope ratios of sulfur and carbon of these rocks in order to determine their origin and environment.

\section{SAMPLES}

The petrographical and geological description and chemical composition of the samples used in this study are presented by Fujioka (this volume). He analyzed the chemical composition of 28 conglomerate specimens from Site 439. These samples are acid to intermediate $\left(60.23-73.90\right.$ per cent $\left.\mathrm{SiO}_{2}\right)$ and are characterized by high alumina content $(15.97-26.80$ per cent). On the basis of the $\mathrm{SiO}_{2}-\mathrm{FeO} / \mathrm{MgO}$ diagram, about two-thirds of them were classified as calc-alkaline rocks and the rest as tholeiitic rocks. Of the five samples we studied, two (Nos. 2 and 10) are tholeiite, another two (15 and 21) are calc-alkaline, and the last (4) lies close to the boundary between the two rock series, according to Fujioka (this volume).

\section{ANALYTICAL METHODS}

We heated powdered rock samples in vacuum at $280^{\circ} \mathrm{C}$ for two hours with "Kiba reagent" ( $\mathrm{Sn}^{2+}$-containing phosphoric acid [Kiba et al., 1955]). Sulfate, sulfide, carbonate, and carbide in the samples are converted to $\mathrm{SO}_{2}, \mathrm{H}_{2} \mathrm{~S}, \mathrm{CO}_{2}$, and some hydrocarbons, respectively, by this procedure. Each component was isolated by a combination of vacuum distillation and chemical fractionation at varying temperatures. Next, the $\mathrm{H}_{2} \mathrm{~S}$ and hydrocarbons were oxidized into $\mathrm{SO}_{2}$ and 
$\mathrm{CO}_{2}$, respectively, using a $\mathrm{Cu}_{2} \mathrm{O}$ furnace. They will be denoted as $\mathrm{SO}_{2}{ }^{*}$ and $\mathrm{CO}_{2}{ }^{*}$, respectively, to distinguish them from those originally evolved from the samples. The volume and isotope ratios of these $\mathrm{SO}_{2}, \mathrm{SO}_{2}{ }^{*}, \mathrm{CO}_{2}$, and $\mathrm{CO}_{2}{ }^{*}$ were measured separately by conventional techniques. The concentrations of sulfate, sulfide, carbonate, and noncarbonate in the samples were calculated from the volumes of these gases. However, because the noncarbonate carbon cannot be measured quantitatively by this method, we eliminate it from the following discussion. We will give the details of these procedures elsewhere.

The isotopic results are given by delta values which are defined as follows:

$$
\delta X=\left(\frac{R_{\text {sample }}}{R_{\text {standard }}}-1\right) \times 1000 \text { per mill, }
$$

where $X={ }^{34} \mathrm{~S}$ or ${ }^{13} \mathrm{C}$ and $R={ }^{34} \mathrm{~S} /{ }^{32} \mathrm{~S}$ or ${ }^{13} \mathrm{C} /{ }^{12} \mathrm{C}$ of a sample and a standard. The standard for sulfur is troilite from the Canon Diablo meteorite and, for carbon, a fossil belemenite from the Peedee Formation of North Carolina.

The isotopic ratios of sulfate and sulfide sulfurs were measured separately only in the case of Sample No. 5 . In other samples, the amount of each of the two types of $\mathrm{SO}_{2}$ was too small for reliable mass spectrometric analyses, and therefore the two $\mathrm{SO}_{2}$ were measured together. The accuracy of the delta values is \pm 0.3 per mill, except for the $\delta^{34} \mathrm{~S}$ of Sample No. 10 and 15, where the sulfur content is too low for accurate measurement.

\section{RESULTS AND DISCUSSION}

The results of the present study are summarized in Table 1 and are plotted in Figures 1 and 2. For comparison, the isotopic ratios of basalts from ocean floors, Hawaii, and Iceland and the isotopic ranges of the island arc volcanic rocks are also shown in these figures.

The sulfur and carbon content of the fresh andesites and basalts of the Japanese Islands is low (generally less than $50 \mathrm{ppm} \mathrm{S}$ and $10-100 \mathrm{ppm} \mathrm{C}$ ) compared to the submarine basalts. Submarine eruption under high stat- ic pressure prevented the loss of volatiles from magma, whereas under subaerial conditions, magma was outgassed to a substantial extent before and/or during eruption (Moore and Fabbi, 1971). In addition, the contents of these volatiles in the Japanese volcanic rocks may have been low even before the outgassing. Moore and Fabbi (1971) estimated about 80 per cent of the original sulfur to have been lost during subaerial eruption of basalt. If the same estimate is applied to island arc volcanism, the maximum sulfur content of andesites and basalts of the Japanese Islands should be about 250 ppm S. The rhyolite and dacite conglomerates are similar in sulfur content to the andesites and basalts of the Japanese Islands, in accord with their subaerial eruption (Fujioka, this volume).

However, the $\delta^{34} \mathrm{~S}$ values of the acid rocks are unexpectedly high, even higher than sea water sulfate $\left(\delta^{34} \mathrm{~S}\right.$ $=20.3$ per mill). As Table 1 shows, the $\delta^{34}$ S value of Sample No. 5 is high for both sulfate and sulfide. Although in other samples $\mathrm{SO}_{2}$ and $\mathrm{SO}_{2}{ }^{*}$ were not measured separately for the sulfur isotope ratios, it is likely that both sulfate and sulfide in these samples are equally enriched in ${ }^{34} \mathrm{~S}$. As Figure 1 shows, the ${ }^{34} \mathrm{~S}$ values of the majority of ocean floor basalts are within a narrow range -0 to +1 per mill, the inferred value for the upper mantle sulfur. In the continental volcanic rocks, the sulfur isotopic ratios tend to be higher than the mantle value, with increasing degree of differentiation. However, the value does not exceed +9 per mill for more than 30 basaltic rocks from Europe (Schneider, 1970). About 40 andesites and basalts from the Japanese Islands show values from 0 to +5 per mill, except for the volcanic rocks from the Satsuma-Iwojima and Aso volcanoes (see Figure 1).

In quite a few samples of ocean floor basalts from the East Pacific Rise, epigenetic pyrites as heavy as +24 per mill have been found (Field et al., 1976). Field et al. (1976) proposed that magmatic sulfur could have been fractionated into such heavy sulfide through partial oxidation of sulfide to sulfate and sulfur isotope fractionation between them. Such a reaction should also produce larger amounts of sulfide, which is closer to or even

TABLE 1

Concentrations and Isotopic Ratios of Sulfur and Carbon in Acid Conglomerates from Hole 439, Leg 57

\begin{tabular}{|c|c|c|c|c|c|c|c|c|c|c|c|c|c|c|}
\hline \multirow[b]{2}{*}{ No. ${ }^{a}$} & \multirow[b]{2}{*}{$\begin{array}{c}\text { Sample } \\
\text { (Interval in } \mathrm{cm} \text { ) }\end{array}$} & \multirow[b]{2}{*}{ Rock Type } & \multicolumn{3}{|c|}{$\underset{(\mathrm{ppm})}{\mathrm{S}}$} & \multicolumn{3}{|c|}{$\begin{array}{c}\delta^{34} \mathrm{~S} \\
\text { (per mill) }\end{array}$} & \multicolumn{3}{|c|}{$\underset{\text { (per mill) }}{\mathrm{CO}_{2}}$} & \multicolumn{3}{|c|}{$\begin{array}{c}\delta^{13} \mathrm{C} \\
\text { (per mill) }\end{array}$} \\
\hline & & & $\mathrm{s}^{2-}$ & $\mathrm{SO}_{4}^{2-}$ & $\Sigma \mathrm{S}^{\mathrm{b}}$ & $\mathrm{s}^{2-}$ & $\mathrm{SO}_{4}^{2-}$ & $\Sigma S$ & $\mathrm{CO}_{3}^{2-}$ & $\mathrm{CnHm}$ & $\Sigma C^{d}$ & $\mathrm{CO}_{3}^{2-}$ & $\mathrm{CnHm}$ & $\mathrm{\Sigma CO}_{2}{ }^{\mathrm{e}}$ \\
\hline 2 & $439-33-1,18-19$ & rhyolite & 15 & 7 & 22 & - & - & +28.8 & 128 & 21 & 149 & -14.5 & -22.4 & -15.6 \\
\hline 4 & $439-33-1,122-124$ & dacite & 16 & 5 & 21 & - & - & +34.7 & 176 & 24 & 200 & -20.7 & -23.1 & -20.9 \\
\hline 10 & $439-34-2,0-4$ & dacite & 0 & 8 & 8 & - & - & +25.9 & 721 & 34 & 755 & -2.5 & -22.8 & -3.4 \\
\hline 15 & $439-34-2,148-150$ & dacite & 3 & 6 & 9 & - & - & +23.3 & 383 & 9 & 392 & -11.5 & -18.7 & -11.6 \\
\hline
\end{tabular}

\footnotetext{
${ }_{b}^{a}$ Corresponds to the sample number of Fujioka (this volume).

${ }_{c}$ Calculated sum of sulfide $\left(\mathrm{S}^{2-}\right)$ and sulfate $\left(\mathrm{SO}_{4}^{2-}\right)$ sulfur.

Weighted average of sulfide and sulfate.

${ }^{d}$ Calculated sum of carbonate $\left(\mathrm{CO}_{3}^{2-}\right)$ and noncarbonate $(\mathrm{CnHm})$ carbon.

${ }^{\mathrm{e}}$ Weighted average of two types of carbon.
} 


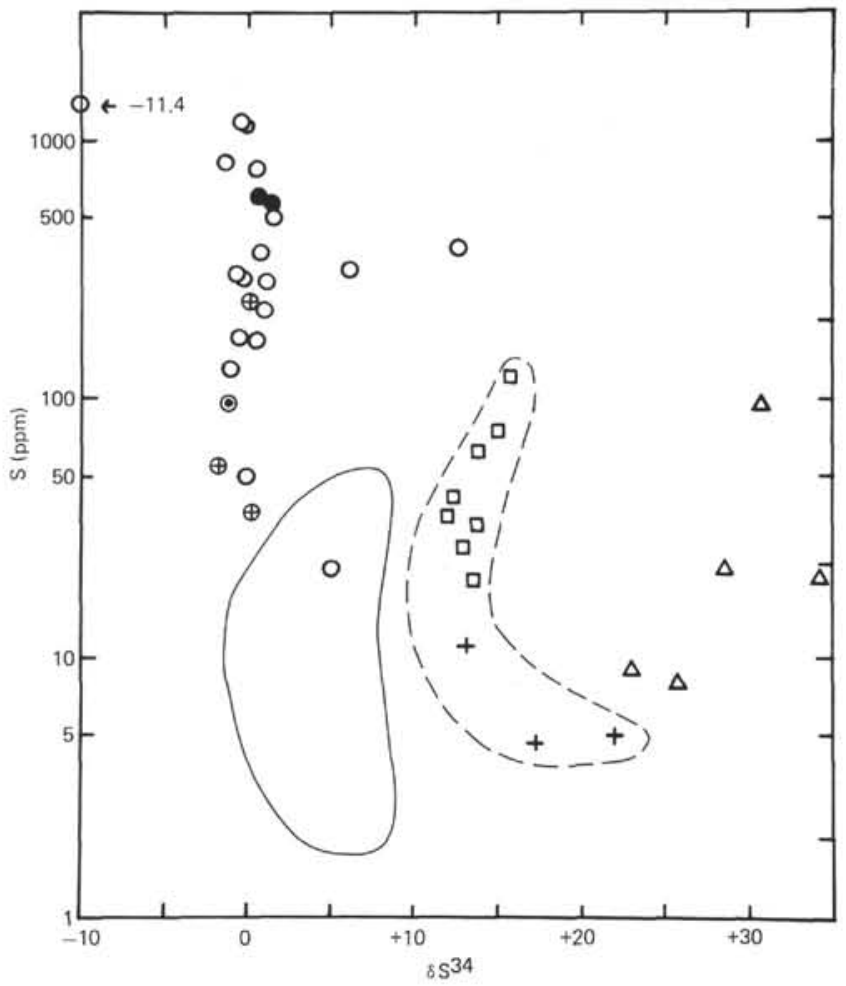

Figure 1. $\delta^{34} S$ versus sulfur concentration diagram for the acid conglomerates from Site 439 and for the basaltic rocks from the Japanese Islands, ocean floor, Hawaii, and Iceland. $\Delta=$ acid conglomerates (this study). $\bigcirc=$ ocean floor basalts (Sakai et al., 1978). - = ocean floor basalts (Grinenko et al., 1975). $\odot$ = Kilauea, Hawaii, erupted on 29 November 1975. Collected by S. Aramaki (Ueda and Sakai, unpublished data). $\oplus=$ Icelandic basalts (Sakai et al., unpublished data). Area enclosed by solid line = about 40 andesites and basalts of the Japanese Islands (Ueda and Sakai, unpublished data). $\square=$ andesites from the Satsuma-Iwojima (see text). + = andesites from the Aso Volcano (see text).

lower in $\delta^{34} \mathrm{~S}$ than the mantle sulfur. This is the case in the ocean floor basalts. However, we found no such light sulfur in the randomly selected samples of the present study.

The heavy sulfur may be formed much more easily from sea water sulfate because its isotopic ratios are already higher than the mantle sulfur. The SatsumaIwojima is a volcanic island composed of the central cones of a giant caldera almost entirely submerged at 400 meters below sea level off southernmost Kyushu. One of the central cones still exhibit fumarolic activity of high temperatures and gives off volatile sulfur compounds - mainly $\mathrm{SO}_{2}$. The isotopic ratios of the $\mathrm{SO}_{2}$ as well as the total sulfur in the fresh andesite lava forming this cone are +13 to +16 per mill (Figure 1). The heavy sulfur probably formed through the incorporation of sea water sulfate into the magmatic processes of the island. It should also be noted in Figure 1 that the andesite samples of the Aso Volcano, which forms

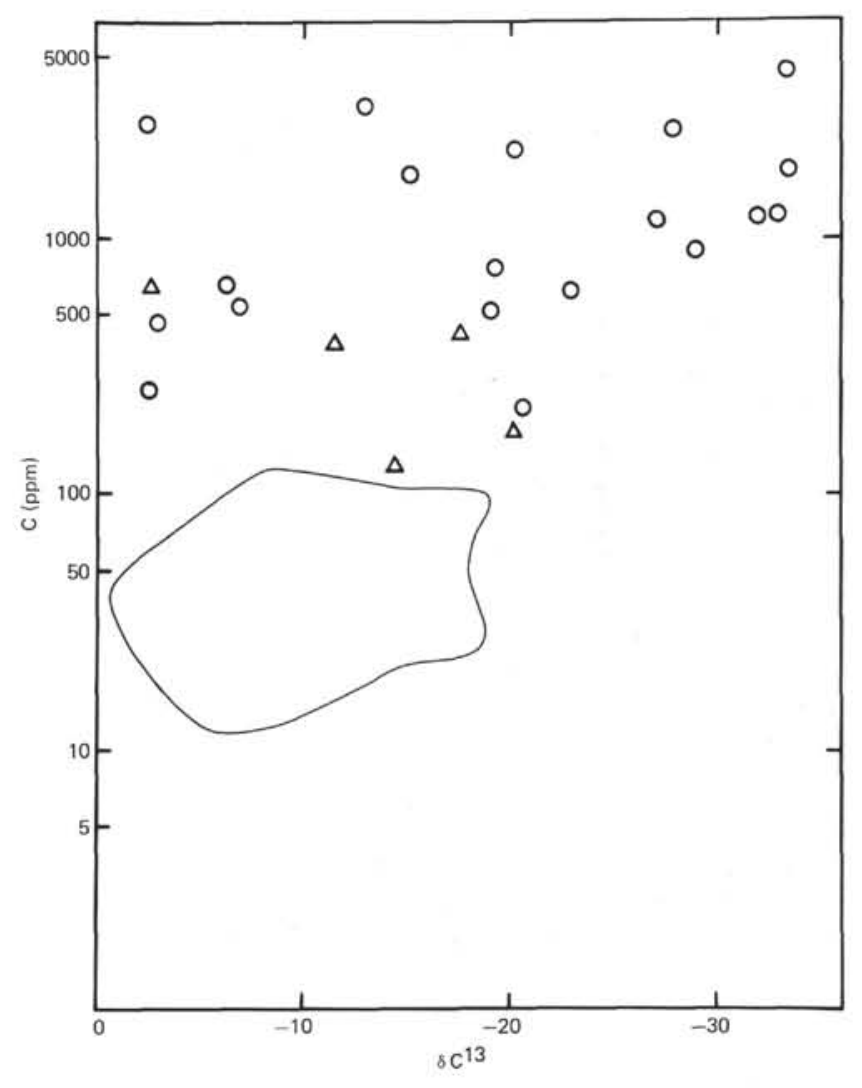

Figure 2. $\delta^{13} C$ versus carbonate carbon content of the acid conglomerates, ocean floor basalts, and Japanese andesites and basalts (see Figure 1 for explanation of symbols).

another giant caldera on the mainland of Kyushu, contain sulfur with high $\delta^{34} \mathrm{~S}$ values. It may be that giant calderas at an ocean island arc interface enhance the incorporation of sea water sulfate into magmatic processes. Another possible source of sulfur is the sedimentary rock through which the acid magma extruded. However, sulfur in the sedimentary rocks underlying the Japanese Islands is generally considered to be much lighter than the present sea water sulfate.

Figure 2 indicates that the acid conglomerates are intermediate in carbonate content and $\delta^{13} \mathrm{C}$ between the island arc and submarine volcanic rocks. Except for Sample No. 10 , the $\delta^{13} \mathrm{C}$ values are between -10 and -20 per mill. On the other hand, the majority of the Japanese volcanic rocks show values higher than -10 per mill. The isotopic ratios of $\mathrm{CO}_{2}$ in volcanic gases of active andesite volcanoes of the Japanese Islands cluster around -5 per mill (Sakai and Matsubaya, 1976). Therefore, we tend to think that the carbon from the upper mantle should have a $\delta^{13} \mathrm{C}$ value of greater than -10 per mill. Sample No. 10 is exceptionally high in both carbonate carbon and ${ }^{13} \mathrm{C}$. Fujioka (this volume) states there is no evidence for marine environment in sedimentary rocks intercalated with the conglomerates of the present study. If there was no contamination of the conglomerate beds by marine biogenic carbonate, this sample should closely duplicate the original carbonate content 
and $\delta^{13} \mathrm{C}$ of the acid magma. The fact that the sulfur content of the sample is the lowest among the five conglomerates makes such a conclusion unlikely, although some carbonate may have precipitated from interstitial water flowing through the conglomerate after deposition.

\section{CONCLUSIONS}

The acid conglomerates at Site $\mathbf{4 3 9}$ have a sulfur content similar to and carbonate content slightly higher than the Quaternary andesites and basalts of the Japanese Islands. However, their $\delta^{34} \mathrm{~S}$ values are much greater. In the more than 40 tholeiitic and calc-alkaline rocks from the Japanese Islands we have analyzed so far, there were no Quaternary volcanic rocks of equally high $\delta^{34} \mathrm{~S}$ values. The sulfur isotopic data indicate that sulfur isotope fractionation involving sea water sulfate played a more significant role in the formation of these acid rocks than it does at present at Satsuma-Iwojima.

\section{ACKNOWLEDGMENTS}

We are indebted to N. Nasu and K. Fujioka of the Ocean Research Institute of Tokyo University for providing us with samples and with detailed information. The research was supported by Grants in Aid for Scientific Research No. 334054 to M. Yamaguchi of Kyushu University.

\section{REFERENCES}

Field, C. W., Dymond, J. R., Heath, G. R., Corliss, J. B., and Dasch, E. J., 1976. Sulfur isotope reconnaissance of epigenetic pyrite in ocean-floor basalts, Leg 34 and elsewhere. In Yeats, R. S., Hart, S. R., et al., Init. Repts. DSDP, 34: Washington (U.S. Govt. Printing Office), 381-384.

Grinenko, V. A., Dmitriev, L. V., Migdisov, A. A., and Sharas'kin, A. Y., 1975. Sulfur contents and isotopic composition of igneous and metamorphic rocks from midocean ridges. Geochem. International, 12, 132-137.

Kanehira, K., Yui, S., Sakai, H., and Sasaki, A., 1973. Sulphide globules and sulphur isotope ratios in the abyssal tholeiite from the Mid-Atlantic Ridge near $30^{\circ} \mathrm{N}$ latitude. Geochem. J., 7, 89-96.

Kiba, T., Takagi, T., Yoshimura, Y., and Kishi, I., 1955. A new reagent for the determination of sulfate by reduction to hydrogen sulfide. Bull. Chem. Soc. Japan, 28, 641-644.

Krouse, H. R., Brown, H. M., and Farqubasson, R. B., 1977. Sulfur isotope compositions of sulphides and sulphates, Deep Sea Drilling Project Leg 37. Canad. J. Earth Sci., 14, 787-793.

Moore, J. G., and Fabbi, B. P., 1971. An estimate of the juvenile sulfur content of basalt. Contr. Mineral. Petrol., 33, 118-127.

Sakai, H., and Matsubaya, O., 1976. Stable isotope studies of Japanese geothermal systems. Geothermics, 5, 67-74.

Sakai, H., Ueda, A., and Field, C. W., 1978. S $^{34}$ S and concentration of sulfide and sulfate sulfurs in some oceanfloor basalts and serpentinites. In R. E. Zartman (Ed.), Short papers, 4th International Conference on Geochronology, Cosmochronology, Isotope Geology, Geol. Survey Open-File Rept. 78-701: Washington (U.S. Govt. Printing Office), pp. 372-374.

Schneider, A., 1970. The sulfur isotope composition of basaltic rocks. Contr. Mineral. Petrol., 25, 95-124. 